\title{
Wear Behavior of Austenitic NiTi Shape Memory Alloy
}

\author{
Lina Yan $^{1} \cdot$ Yong Liu ${ }^{1}$
}

Published online: 21 April 2015

(C) ASM International 2015

\begin{abstract}
This study aims to understand the wear behavior of austenitic NiTi SMA with the hope to provide a guideline for its better use for wear-resist purposes. Ballon-disk sliding wear tests with alumina counter ball were conducted at different temperatures and under different loads. Based on the coefficients of friction, the surface wear features, temperature-dependent stress-strain curves and the estimated contact stresses, the deformation mechanisms involved in the wear process were examined. Two wear modes were identified. Mode I is temperaturesensitive and occurred when $A_{\mathrm{f}}<T<M_{\mathrm{d}}$. In this mode, wear process was dominated by the interplay among contact stress, temperature and shape recovery property. Results show that, when the contact stress causes either elastic deformation of austenite or stress-induced martensitic transformation, the wear resistance was improved with increasing temperature. This was originated from increased critical stress for stress-induced martensite which retards plastic deformation. However, when contact stress is higher than yield stress of stress-induced martensite, wear resistance is deteriorated. Mode II occurs when $T>M_{\mathrm{d}}$ and it is less temperature-sensitive within the testing range. In this mode, the austenitic NiTi loses its superelasticity and obeys a conventional deformation sequence, and the key factor dominating the wear process is the magnitude of contact stress.
\end{abstract}

Yong Liu

mliuy@ntu.edu.sg

1 School of Mechanical and Aerospace Engineering, Nanyang Technological University, 50 Nanyang Avenue, Singapore, Singapore
Keywords NiTi shape memory alloy $\cdot$ Phase transformation $\cdot$ Wear $\cdot$ Sliding friction

\section{Introduction}

NiTi shape memory alloy (SMA) has been widely investigated for tribology related applications due to its superior wear resistance reported in both martensitic and austenitic phases $[1,2]$. Owing to the combined properties of wear resistance, corrosion resistance and biocompatibility, biomedical devices such as NiTi needle, NiTi superelastic arch wire and shape memory attachment for partial denture have been successfully developed [1-9]. In addition, the NiTi SMAs possessing shape memory effect and vibrationdamping features have also been proposed as a new candidate material for robots and smart material actuators, as well as for the micro-electro-mechanical system (MEMS) devices $[10,11]$.

In the previous studies on the wear behavior of NiTi SMAs, effects of wear mode, applied load, and counterwear materials have been reported [1-11]. Although the hardness of NiTi SMA is much lower, better wear resistance has been reported as compared with conventional wear-resist materials such as GCr15 steel, Al2024 and Co45 alloy [10-17]. For conventional wear-resist materials, hardness is the predominant factor that determines their wear resistance. However, for NiTi SMAs, the temperature-related superelasticity (also known as pseudoelasticity) has been suggested as the predominant factor that determines the wear resistance. It is known that the microstructure of NiTi SMA is temperature-dependent which further leads to the temperature-dependence of the deformation mechanisms involved in the wear process. When $T<M_{\mathrm{f}}$, the good wear resistance in martensitic NiTi SMA 
has been attributed to the deformation strain accommodation through detwinning process, which is accompanied by a stress-plateau in the stress-strain curve. When $A_{\mathrm{f}}<$ $T<M_{\mathrm{d}}$, the good wear resistance of austenitic NiTi SMA has been attributed to the deformation strain accommodation through a stress-induced martensitic transformation (SIMT) process which is accompanied by a reversible stress-strain curve $[10,15]$.

According to the Clausius-Clapeyron equation, the critical stress for stress-induced martensitic transformation increases with increasing temperature $[18,19]$. However, when the temperature is above $M_{\mathrm{d}}$ which is the highest temperature for SIMT, dislocation can be generated prior to stress-induced martensitic transformation [20]. The fretting wear resistance of NiTi SMA has been reported to have decreased when the temperature was increased above $M_{\mathrm{d}}$ [21]. The dislocation generation has dominated the wear process when the temperature exceeded $M_{\mathrm{d}}$ and caused increased amount of fretting wear. In addition, researchers have studied the wear behavior of austenitic NiTi SMA possessing different values of critical stress for SIMT, but found no obvious difference in the wear resistance $[12,14$, $16,17]$. The extremely high applied load has been suggested as the predominant factor to determine the wear behavior, and similar deformation mechanisms were proposed to have been involved.

The wear behavior of austenitic NiTi SMA is dependent on the deformation mechanisms involved in the wear test, while the deformation mechanism depends on the interplay between the contact stress/applied load and the test temperature. Several wear studies have reported the effect of superelasticity on the wear resistance of austenitic NiTi SMA [12, 14, 16, 21]. However, the effect of temperature and applied load on the deformation mechanisms involved in the wear process has rarely been discussed. We have previously reported the wear behavior of NiTi SMA and controlling factors in the martensitic state [22] and across the transformation temperature range [23]. In the present research, in order to fundamentally understand the deformation mechanisms involved in the wear process and reveal the predominant factor contributing to the wear resistance of austenitic NiTi SMA, micro-scale wear tests were conducted at different loads and temperatures. The coefficient of friction as a function of wear cycles was used to analyze the plastic strain accumulation process. Meanwhile, the corresponding surface wear features were imaged by confocal microscope to quantitatively estimate the surface damage. The deformation mechanisms involved in the wear process were discussed through taking into consideration the contact stresses as a function of applied load and the corresponding deformation regions in the temperature-dependent stress-strain curves. As a result, different wear modes associated with different deformation mechanisms were identified, and ways on how to improve the wear resistance of austenitic NiTi SMA were proposed.

\section{Experimental}

Commercially available flat $\mathrm{NiTi}$ plate with size of $120 \mathrm{~mm} \times 60 \mathrm{~mm} \times 1 \mathrm{~mm}$ has been cut into samples of $10 \mathrm{~mm} \times 10 \mathrm{~mm} \times 1 \mathrm{~mm}$ for wear test. The samples were annealed at $600{ }^{\circ} \mathrm{C}$ for $30 \mathrm{~min}$ to eliminate the R-phase. The transformation temperatures were determined using a TA instruments Q200 differential scanning calorimeter (DSC) at a heating rate of $2{ }^{\circ} \mathrm{C} / \mathrm{min}$. The DSC result is shown in Fig. 1a, in which the martensitic starting $\left(M_{\mathrm{s}}\right)$ and finishing $\left(M_{\mathrm{f}}\right)$ temperatures were $-18^{\circ} \mathrm{C}$ and $-44{ }^{\circ} \mathrm{C}$, and the austenitic starting $\left(A_{\mathrm{s}}\right)$ and finishing $\left(A_{\mathrm{f}}\right)$ temperatures were $-16{ }^{\circ} \mathrm{C}$ and $6{ }^{\circ} \mathrm{C}$, respectively. Samples were grinded with sand papers to remove the oxide layers,
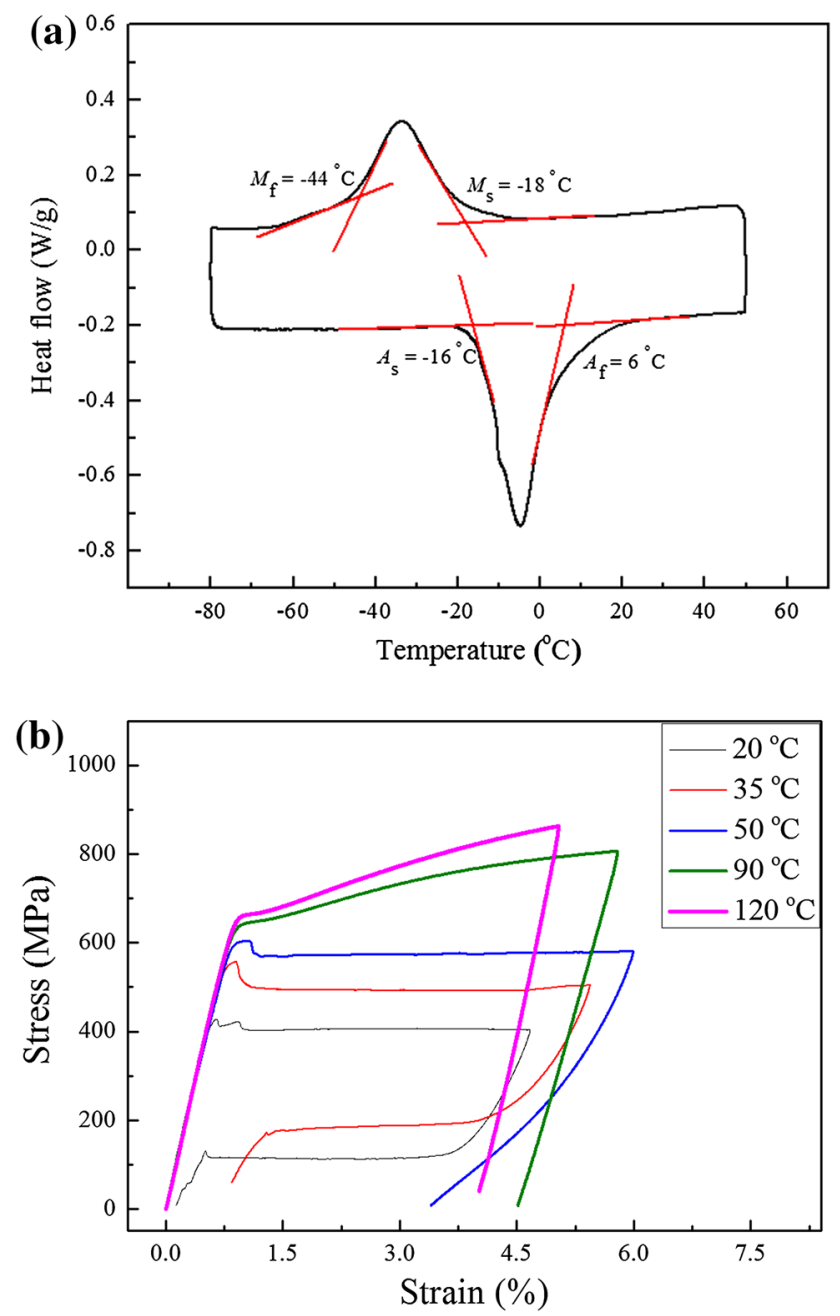

Fig. 1 a DSC curve of the tested NiTi SMA with phase transformation temperatures indicated. b The stress-strain curves of austenitic NiTi SMA obtained at temperatures ranged from 20 to $120{ }^{\circ} \mathrm{C}$ 
and were polished with diamond paste to reduce the surface roughness. The bare NiTi samples were held at $150{ }^{\circ} \mathrm{C}$ for $10 \mathrm{~min}$ to release the residual strain. Thereafter, the surfaces were examined by using a DI3000 atomic force microscope (AFM) under tapping mode. Only samples with surface roughness $(\mathrm{Ra})$ value below $15 \mathrm{~nm}$ were used in the subsequent wear tests. According to Firstov et al. [24], near-zero oxidation occurred on bare NiTi surface when heat treatment was conducted at temperatures below $300{ }^{\circ} \mathrm{C}$. Therefore, the formation of new oxidized layer on the bare NiTi surface was negligible in the present study.

Ball-on-disk sliding wear tests were conducted on the tribometer with CETR UMT multi-specimen test system, and alumina counter-ball $\left(\mathrm{Al}_{2} \mathrm{O}_{3}\right)$ having diameter of $4 \mathrm{~mm}$ was used. The sliding speed was at $4.71 \mathrm{~mm} \mathrm{~s}^{-1}$, and the sliding distance was estimated to be $9,420 \mathrm{~mm}$ for 1,000 wear cycles. The test temperature was ranged from 20 to $120{ }^{\circ} \mathrm{C}$ and the applied load was ranged from 50 to 300 $\mathrm{mN}$, respectively. In each test, the temperature was determined by using a thermal couple that is in direct contact with the sample surface before running the wear test. Local temperature rise may be involved in the wear process. However, since the precise measurement of the instant temperature is a challenging problem in wear study, the present study has used micro-scale wear tests under low sliding speed in order to minimize the local temperature rise. After each test, Nikon Eclipse L150 laser confocal microscope was used to examine the surface wear features.

To determine the effect of temperature on the stressstrain curves of austenitic NiTi SMA, tensile tests were conducted on the Instron 5569 UT M/C equipped with a temperature chamber. Dog bone-shaped samples with size of $120 \mathrm{~mm} \times 2 \mathrm{~mm} \times 1 \mathrm{~mm}$ were prepared from the NiTi plate. The strain rate was at $0.001 \mathrm{~s}^{-1}$, hence the effect of strain rate on the stress-strain curve was minimized [25]. The maximum deformation strain was set at around $6 \%$ for tests at different temperatures.

\section{Results}

In the present study, wear tests were performed at various temperatures at which the NiTi SMA remains austenitic. Effects of temperature and applied load on the coefficient of friction and surface wear features were systematically investigated. In order to understand the observations of temperature-dependence and load-dependence of the wear behavior, the temperature-dependence of the stress-strain curve was determined and the contact stresses were estimated. As a result, the corresponding deformation mechanisms were identified and were used to explain the experimental observations. In the following, the coefficients of friction and surface wear features as a function of applied load and test temperature were presented together with the stress-strain curves obtained at different temperatures.

\section{Stress-Strain Curves at Various Temperatures}

The stress-strain curves obtained at temperatures that ranged from 20 to $120{ }^{\circ} \mathrm{C}$ are presented in Fig. 1b. Fully austenitic phase is present in the test temperature range. As shown in Fig. $1 \mathrm{~b}$, when tested at $20^{\circ} \mathrm{C}$, a nearly perfect superelasticity exists in the present material. The upper and lower stress-plateaus were associated with the forward and reverse SIMT, respectively. With increasing the temperature, the critical stress for SIMT increases which can be understood based on the Clausius-Clapeyron equation. At $50{ }^{\circ} \mathrm{C}$, the upper stress-plateau still exists suggesting the occurrence of the SIMT at this temperature. However, when the temperature was increased to $90{ }^{\circ} \mathrm{C}$ and above, the stress-plateau disappeared; instead, a conventional strain-hardening process was observed. Since the SIMT was suppressed at 90 and $120^{\circ} \mathrm{C}$, the plastic deformation of austenitic NiTi had occurred. This suggests that $M_{\mathrm{d}}$ temperature was reached/exceeded. In addition, from Fig. 1b, at different temperatures, the calculated values of the elastic modulus of the present material were in between 70 and $80 \mathrm{GPa}$, which are comparable with the reported values [20].

In Fig. 1b, the shape recovery strain shows a decreasing tendency with increasing temperature from 20 to $120^{\circ} \mathrm{C}$. The data of the critical stress for SIMT, the yield stress of austenite, and the recovery ratio $(R)$ as a function of temperature are listed in Table 1 in which the recovery ratio was calculated by using Eq. (1):

$R=\frac{\left(\varepsilon_{\max }-\varepsilon_{\mathrm{res}}\right)}{\varepsilon_{\max }}$

where, $\varepsilon_{\max }$ is the maximum strain and $\varepsilon_{\text {res }}$ is the residual strain.

According to the Clausius-Clapeyron equation, the relation between critical stress for SIMT and the temperature is expressed by Eq. (2) [26]:

$\frac{d \sigma}{d T}=\frac{-\Delta H}{\left(T \cdot \varepsilon_{0}\right)}$

Table 1 Summary of the critical stress for stress-induced martensitic transformation, the yield stress of austenite, and shape recovery ratio at different temperatures

\begin{tabular}{llllll}
\hline Temp & $20{ }^{\circ} \mathrm{C}$ & $35{ }^{\circ} \mathrm{C}$ & $50{ }^{\circ} \mathrm{C}$ & $90{ }^{\circ} \mathrm{C}$ & $120{ }^{\circ} \mathrm{C}$ \\
\hline$\sigma_{\text {cri }}(\mathrm{MPa})$ & 404 & 495 & 572 & 646 & 668 \\
$R$ & 0.95 & 0.86 & 0.44 & 0.22 & 0.22 \\
\hline
\end{tabular}


where, $\sigma$ is the stress; $\Delta H$ is the transformation latent heat (or enthalpy of the transformation per unit volume); $T$ is the temperature and $\varepsilon_{0}$ is the amount of strain due to stressinduced martensitic transformation.

McKelvey and Ritchie [27] have studied the effect of temperature on the critical stress for SIMT, and the Eq. (2) is modified to Eq. (3) and (4):

$\frac{d \sigma^{T}}{d T}=\frac{-\left(\Delta h \cdot \rho_{A}\right)}{\left(T \cdot \varepsilon^{T}\right)}$

$\sigma^{T}-\sigma_{0}=\frac{-\left(\Delta h \cdot \rho_{A}\right)}{\varepsilon^{T}} \cdot \ln \left(\frac{T}{T_{0}}\right)$

When tested at 20,35 , and $50{ }^{\circ} \mathrm{C}$, the observed values of the critical stress for SIMT agreed well with the ClausiusClapeyron equation. The $(\mathrm{d} \sigma / \mathrm{d} T)$ value for the stress-induced martensitic transformation was at around $5.6 \mathrm{MPa} \mathrm{K}{ }^{-1}$, which is comparable to the reported range of around 5-8 $\mathrm{MPa} \mathrm{K}^{-1}$ [26-28].

\section{Coefficient of Friction as a Function of Wear Cycles, Applied Load and Temperature}

The coefficient of friction is proportional to the frictional force and is determined by the deformation mechanisms involved in the wear process. Figure 2 summarized the typical behavior of the coefficients of friction as a function of wear cycles, applied load, and test temperature. All the tests shown in Fig. 2 have been repeated and similar trends were observed.

When tested at $20^{\circ} \mathrm{C}$ (Fig. 2a), under $50 \mathrm{mN}$, the coefficient of friction was maintained at around 0.2 to 0.3 for up to 1,000 wear cycles. Under $100 \mathrm{mN}$, the coefficient of friction had increased to around 0.75 after approximately 100 wear cycles. Thereafter, it gradually decreased to about 0.43 after 1,000 wear cycles. With increasing the load from 50 to $100 \mathrm{mN}$, different trends in the coefficient of friction were recorded, suggesting a transition in the deformation mechanisms. Under $200 \mathrm{mN}$, the coefficient of friction had reached to around 0.8 after approximate 100 wear cycles, thereafter it decreased and stabilized at around 0.53 in the remainder of test. When under $300 \mathrm{mN}$, the coefficient of friction had reached to around 0.7 after approximately 170 wear cycles. With further increasing wear cycles, the coefficient of friction had slightly decreased and maintained at about 0.51 for up to 1,000 wear cycles.

When the test temperature was increased to $35^{\circ} \mathrm{C}$, under $50 \mathrm{mN}$, the coefficient of friction was very low, being around 0.07 throughout the test. Under $100 \mathrm{mN}$, the coefficient of friction was also relatively low; it started at around 0.15 and gradually increased to around 0.23 after 1,000 wear cycles. Under $200 \mathrm{mN}$, the trend of the coefficient of friction had changed drastically; it quickly increased to around 0.65 after approximately 250 wear cycles, and decreased to about 0.55 after 1,000 wear cycles. The trend is somehow similar to the result obtained at $20{ }^{\circ} \mathrm{C}$ under $300 \mathrm{mN}$. When the load is further increased to $300 \mathrm{mN}$, the wear test was highly unstable which is likely caused by the severe surface damage, hence the test was stopped after around 380 wear cycles. Comparing with the observations of the coefficient of friction at $20{ }^{\circ} \mathrm{C}$, the wear process at $35{ }^{\circ} \mathrm{C}$ under $50 \mathrm{mN}$ and $100 \mathrm{mN}$ was retarded. This is likely associated with the increase in the critical stress for stress-induced martensitic transformation and will be discussed further in "Discussion" section.

When the temperature was further increased to $50{ }^{\circ} \mathrm{C}$ (Fig. 2c), under $50 \mathrm{mN}$, the coefficient of friction had remained at a low value of around 0.18 for up to 1,000 wear cycles. Under $100 \mathrm{mN}$, the coefficient of friction had increased slightly; it reached to around 0.29 after 200 wear cycles and stabilized at about 0.25 for up to 1,000 wear cycles. Under $200 \mathrm{mN}$, the coefficient of friction had kept at around 0.2 for 300 wear cycles; thereafter it increased to about 0.7 from 600 wear cycles onwards. When the load was increased to $300 \mathrm{mN}$, the wear test was highly unstable thus the test was stopped at about 180 wear cycles. For tests at 35 and $50{ }^{\circ} \mathrm{C}$, similar trends were observed which suggest that similar deformation mechanisms were involved at these two temperatures.

When the temperature was further raised to $90{ }^{\circ} \mathrm{C}$ (Fig. 2d), under $50 \mathrm{mN}$, the coefficient of friction had maintained at around 0.3 throughout the test. Under 100 $\mathrm{mN}$, the coefficient of friction was around 0.6 after 100 wear cycles, which is considerably high if comparing with the previous results obtained at lower temperatures. It started to decrease from around 700 wear cycles and reached at about 0.4 at the end of the test. When the load was increased to $200 \mathrm{mN}$, the coefficient of friction has further increased to as high as 0.72 during the test. With further increasing the load to $300 \mathrm{mN}$, the wear test was highly unstable and was stopped after around 70 wear cycles. The trend of coefficients of friction at $90{ }^{\circ} \mathrm{C}$ is very different from what have been observed at 20, 35 and $50{ }^{\circ} \mathrm{C}$. Since $90{ }^{\circ} \mathrm{C}$ has exceeded the highest temperature for SIMT $\left(M_{\mathrm{d}}\right)$, plastic deformation of austenitic NiTi is likely the predominant deformation mechanism involved in the wear process.

When further tested at $120^{\circ} \mathrm{C}$ (Fig. 2e), the overall trend in the coefficient of friction is somehow similar to that observed at $90{ }^{\circ} \mathrm{C}$ with slight variations. Under $50 \mathrm{mN}$, the coefficient of friction had increased to around 0.68 after approximately 100 wear cycles and thereafter, it remained at around 0.3 in further wear cycles. Under $100 \mathrm{mN}$, the coefficient of friction reached to around 0.5 after approximately 120 wear cycles, followed by a gradual decrease to about 0.3 . Under $200 \mathrm{mN}$, the trend of coefficient 


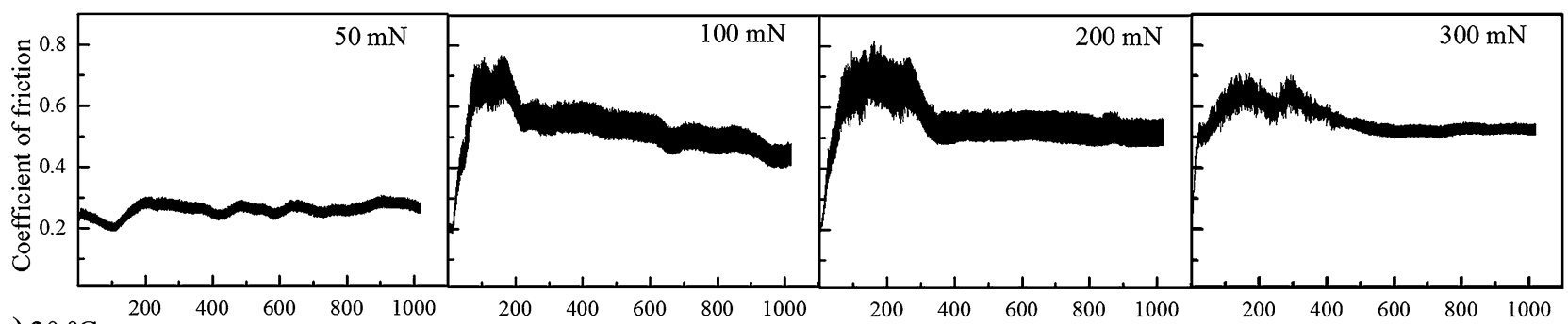

(a) $20{ }^{\circ} \mathrm{C} \quad$ Number of wear cycles

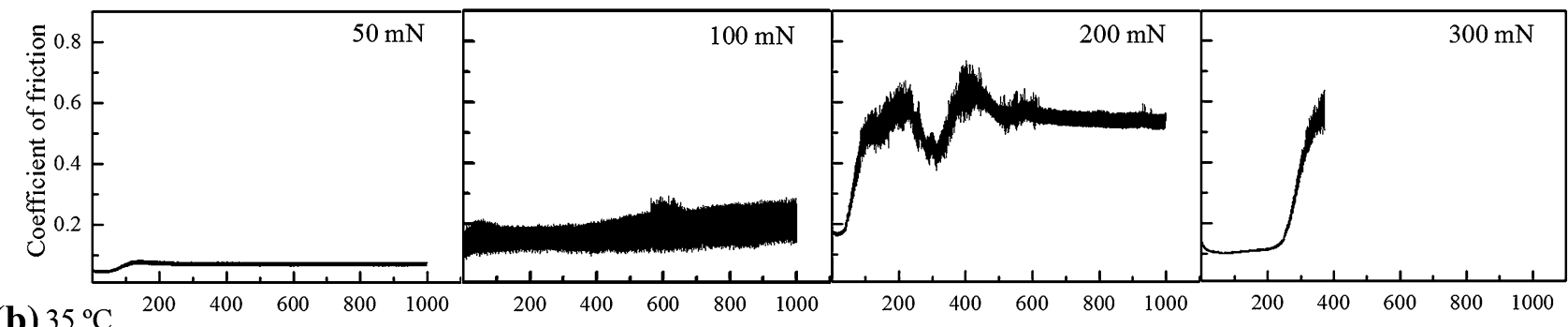

(b) $35^{\circ} \mathrm{C}$

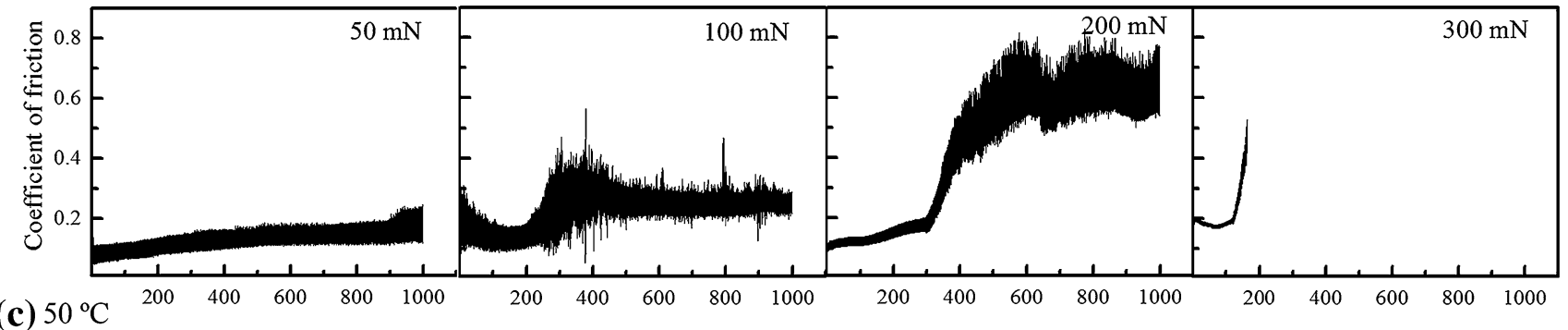

(c)
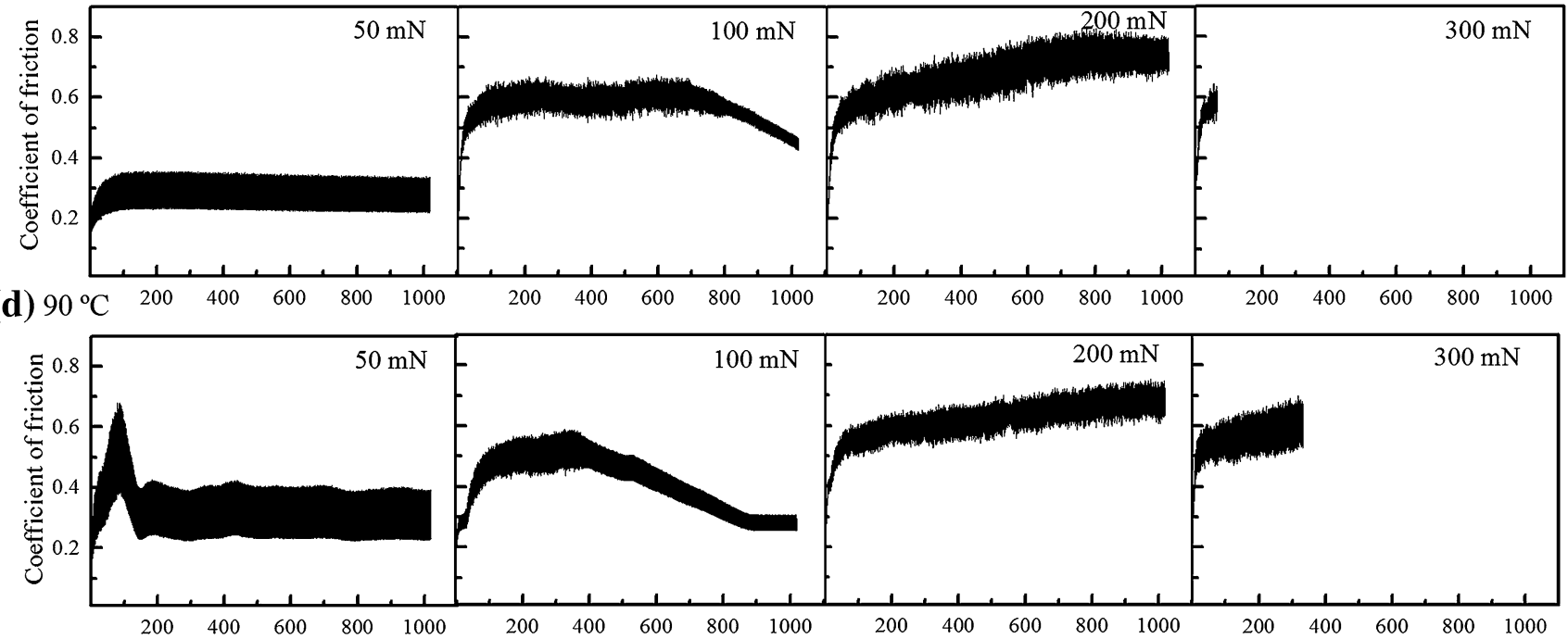

(e) $120^{\circ} \mathrm{C}$ Number of wear cycles

Fig. 2 Coefficient of friction as a function of wear cycles, a at $20{ }^{\circ} \mathrm{C}$ under various loads; $\mathbf{b}$ at $35{ }^{\circ} \mathrm{C}$ under various loads; $\mathbf{c}$ at $50{ }^{\circ} \mathrm{C}$ under various loads; $\mathbf{d}$ at $90{ }^{\circ} \mathrm{C}$ under various loads and, e at $120{ }^{\circ} \mathrm{C}$ under various loads

of friction is very similar to that observed at $90{ }^{\circ} \mathrm{C}$. When tested at $300 \mathrm{mN}$, the wear test was highly unstable and the test was stopped after around 350 wear cycles. Similar observations in the coefficients of friction between 90 and $120{ }^{\circ} \mathrm{C}$ further confirmed the change of deformation mechanism when the temperature exceeded $M_{\mathrm{d}}$.
It is known that, in the beginning of wear test, when two surfaces approaching each other, the high asperities on the surface are getting into contact first [22, 29]. With increasing wear cycles, surfaces adapt to each other through plastic deformation of high asperities, and this period is defined as run-in period. With further increasing wear 


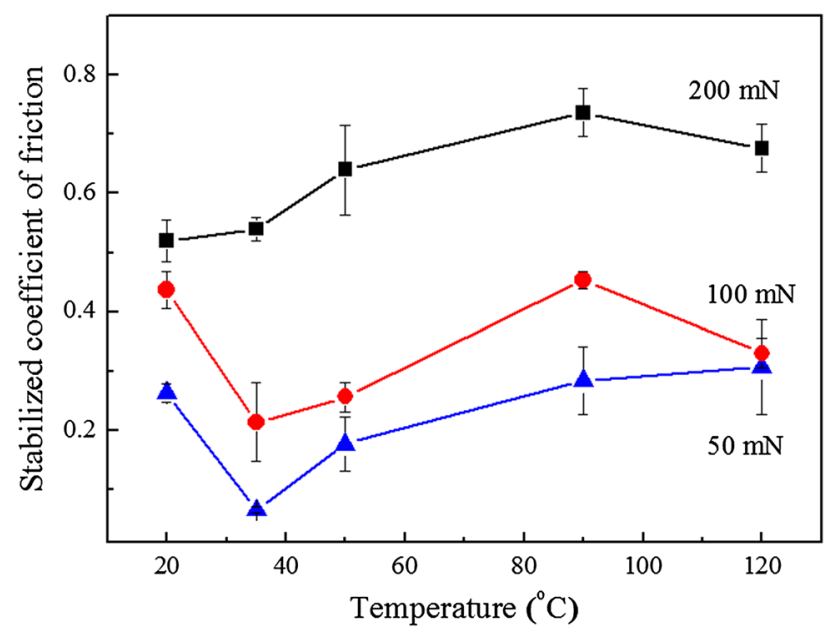

Fig. 3 The values of stabilized coefficient of friction after 1,000 wear cycles for tests under different loads and temperatures shown

cycles, the wear process can be stabilized and the corresponding coefficient of friction is determined by the deformation mechanism of the material.

The values of the stabilized coefficient of friction at $1,000^{\text {th }}$ wear cycles as a function of load and temperature are summarized in Fig. 3. The results under $300 \mathrm{mN}$ were not plotted since tests were stopped before 1,000 wear cycles. The clear trends in the values of the stabilized coefficient of friction as a function of load and temperature indicate transition in the deformation mechanisms. When tested under 50 and $100 \mathrm{mN}$, the values of stabilized coefficient of friction at 35 and $50{ }^{\circ} \mathrm{C}$ were lower than that at $20{ }^{\circ} \mathrm{C}$. This is likely due to the increased critical stress for SIMT which retarded further plastic deformation. When the temperature was increased to 90 and $120{ }^{\circ} \mathrm{C}$, the high coefficients of friction were likely caused by plastic deformation. When tested under $200 \mathrm{mN}$, the values of the stabilized coefficient of friction had kept increased with increasing temperature from 20 to $120^{\circ} \mathrm{C}$. This is likely related to the decreased strain accommodation through the reversible SIMT process at increased temperature and will be further discussed.

\section{Surface Wear Features}

The deformation mechanism determines the wear process thus also determines the amount of surface damage. In the present study, micro-scale wear tests were conducted and the amount of material loss was rather small. The surface wear features corresponding to the coefficients of friction shown in Fig. 2 were imaged by using a confocal microscope (Fig. 4). For imaging each surface wear feature, an area of $0.7 \times 0.5 \mathrm{~mm}^{2}$ was scanned. Clear trends of the surface damage as a function of load and temperature are seen in Fig. 4. The height of asperities, depth of tracks and width of tracks were quantitatively measured based on plots of the cross-sectional profile.

When tested at $20{ }^{\circ} \mathrm{C}$ under $50 \mathrm{mN}$, asperities were embossed on surface which formed a crown-like structure [22]. Partial of this structure is shown in Fig. 4a. With increasing the load to $100 \mathrm{mN}$, the crown-like structure was destructed and tracks/debris were formed. When the load was increased to 200 and $300 \mathrm{mN}$, increased amount of debris and tracks appeared on surface.

With increasing the temperature to 35 and $50{ }^{\circ} \mathrm{C}$, no visible wear track was found when tested under $50 \mathrm{mN}$, while the crown-like structure was observed when tested under $100 \mathrm{mN}$. With further increasing the load, increased amount of debris and tracks were found. Comparing with the surface wear features at $20{ }^{\circ} \mathrm{C}$, the wear process was apparently retarded when the temperature was increased to 35 and $50{ }^{\circ} \mathrm{C}$. When tested at 90 and $120^{\circ} \mathrm{C}$, the formation of large amount of surface damage was attributed to the plastic deformation which dominated the wear process.

A typical cross-sectional profile of the wear track is shown in Fig. 5a, where the asperities and tracks were distributed non-uniformly. The total cross-sectional area of asperities was estimated by calculating the total area of the peaks as indicated in the gray colored area in Fig. 5a. The average cross-sectional area of the surface asperities was obtained by averaging readings from ten different profiles arbitrarily selected on each wear feature. Similarly, the average area of tracks was also estimated, and the value was smaller than that of the surface asperities. Furthermore, the areas of asperities and tracks are getting close to each other when the applied load was increased to $200 \mathrm{mN}$. This can be attributed to the limited resolution of confocal microscope since some tracks were blocked by surface asperities when the wear was insignificant. The highresolution atomic force microscopic image of the crownlike structure was reported in our previous study [22], and small tracks existed between asperities were not differentiable on the confocal image.

The wear volume was estimated by multiplying the average cross-sectional area of asperities with the length of wear track (Fig. 5b). Since the ball-on-disk sliding wear tests were conducted with track radius of $1.5 \mathrm{~mm}$, the length of track was estimated to be $9.42 \mathrm{~mm}$.

Comparing Figs. 3 and 5, the estimated wear volume has nearly the same trend as that of the corresponding stabilized coefficients of friction as a function of load and temperature. This observation further confirms that the change in the deformation mechanism as a function of load and temperature is responsible for the change in the wear behavior. 

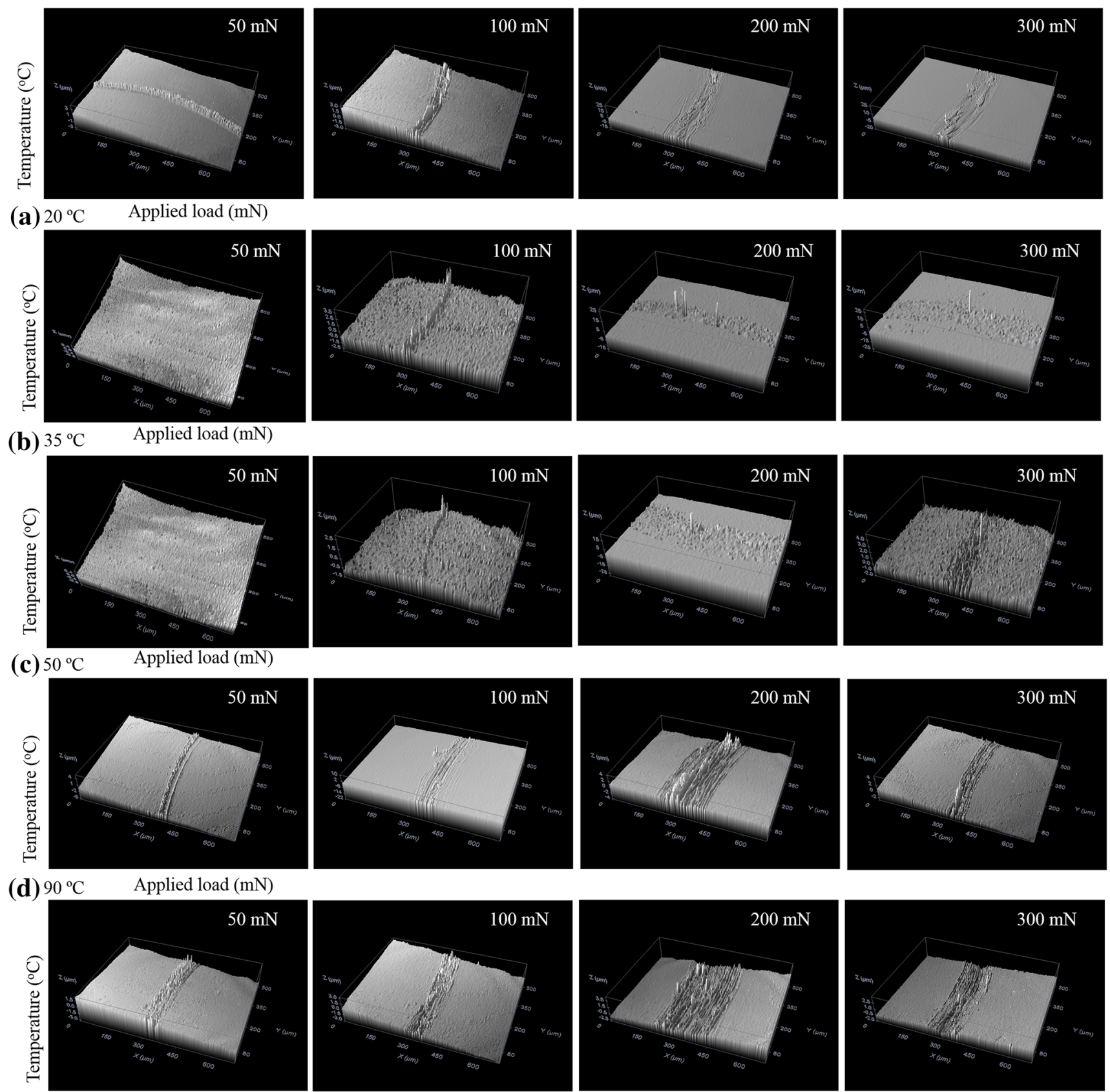

(e) $120^{\circ} \mathrm{C} \quad$ Applied load $(\mathrm{mN})$

Fig. 4 The 3-D confocal microscopic images of the surface wear features after each test, $\mathbf{a}$ at $20{ }^{\circ} \mathrm{C}$ under various loads; $\mathbf{b}$ at $35{ }^{\circ} \mathrm{C}$ under various loads; $\mathbf{c}$ at $50{ }^{\circ} \mathrm{C}$ under various loads; $\mathbf{d}$ at $90{ }^{\circ} \mathrm{C}$ under various loads and, e at $120{ }^{\circ} \mathrm{C}$ under various loads

\section{Discussion}

\section{Deformation Mechanisms of Austenitic NiTi SMA}

It is well known that, although the crystal structure of austenitic NiTi SMA does not change with increasing temperature, the mechanical properties are varied due to change of deformation mechanisms.
When $A_{\mathrm{f}}<T<M_{\mathrm{d}}$, the deformation of austenitic NiTi SMA under a tensile load proceeds through, (1) elastic deformation of austenite, (2) stress-induced martensitic transformation with occurrence of a stress-plateau on the stress-strain curve, (3) elastic deformation of stress-induced martensite and (4) plastic deformation of stress-induced martensite. When $T>M_{\mathrm{d}}$, the deformation proceeds through, (1) elastic deformation of austenite and (2), plastic 

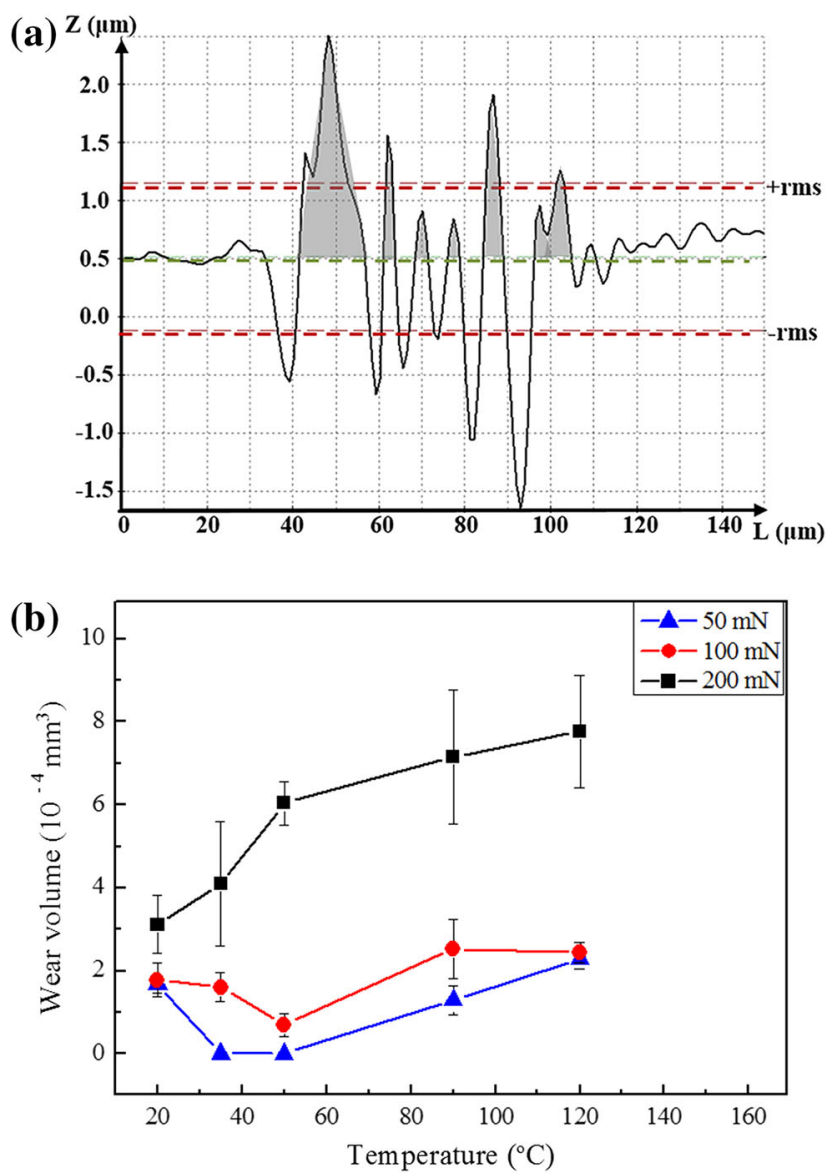

Fig. 5 a A cross-sectional profile of the surface wear track obtained from confocal microscope; b estimated surface wear volume as a function of load and temperature

deformation of austenite associated with dislocation generation.

Under a compressive load, the same deformation sequences were reported, accompanied with higher yield stress in polycrystals [30-33]. In addition, high dislocation density might pin and stabilize the austenite phase hence oppose its further transformation to martensite, meanwhile the reversed transformation process might also be restricted $[31,34]$.

On the other hand, based on the stress-strain curves in Fig. 1b, the deformation mechanism that is operative during wear test is also dependent on the magnitude of contact stress which is determined by the applied load when other parameters remain unchanged. Under ball-on-disk contact model, the contact stress distribution in the vicinity of the contact area is non-uniform [22,34]. The highest contact stress occurs in the contact tip (herein refers to the contact area that is closest to the tip of the counter-ball) at which the deformation is the largest. Therefore, the deformation mechanism in the most deformed area dominates the surface wear process. With increasing distance from the contact tip, the contact stress decreases and this results in less surface damage.

The Hertzian elastic contact model was used to estimate the average contact stress by using Eqs. (5) and (6) [2, 35].

$\sigma^{3}=\frac{6 F_{n}\left(E^{*}\right)^{2}}{\left(\pi^{3} r^{2}\right)}$

$\frac{1}{E^{*}}=\frac{\left(1-v_{1}^{2}\right)}{E_{1}}+\frac{\left(1-v_{2}^{2}\right)}{E_{2}}$

where $\sigma$ is the contact stress, $F_{\mathrm{n}}$ is the applied load, $r$ is the radius of the sphere $(2 \mathrm{~mm}), E_{1}$ and $E_{2}$ are the elastic moduli of the austenitic NiTi and the alumina ball $\left(\mathrm{Al}_{2} \mathrm{O}_{3}\right)$ with values of $75 \mathrm{GPa}$ and $375 \mathrm{GPa}$, respectively. In addition, $v_{1}$ and $v_{2}$ are the Poisson's ratio of the austenitic NiTi and alumina with values of 0.33 and 0.23 , respectively. It is worth to note that the Hertzian elastic contact model can only predict the average contact stress for elastic deformation.

\section{Wear Behavior When $A_{\mathrm{f}}<T<M_{\mathrm{d}}$}

In this temperature regime, three temperatures were selected, i.e., 20,35 , and $50{ }^{\circ} \mathrm{C}$, which correspond to different critical stresses for stress-induced martensitic transformation and different shape recovery ratio in the reversed transformation process. The effect of temperature on the deformation mechanisms will be discussed through taking into consideration the contact stresses involved.

When the average contact stress is below the critical stress for SIMT, elastic deformation dominates the contact area thus causes insignificant wear after repeated wear cycles. This explains the observations on the coefficients of friction and surface wear features when tested under extremely low load. For example, when tested at $20^{\circ} \mathrm{C}$ under $50 \mathrm{mN}$, the coefficient of friction had maintained below 0.3 and insignificant surface wear was observed, being around $1.7 \times 10^{-4} \mathrm{~mm}^{3}$ after 1000 wear cycles (Figs. 2a, 5). By using Eq. (5) and Eq. (6), the calculated average contact stress under the load of $50 \mathrm{mN}$ was $230 \mathrm{MPa}$. This value is lower than the critical stress for SIMT at $20{ }^{\circ} \mathrm{C}$ (404 MPa), which further confirms that the elastic deformation has dominated the wear process under above condition.

When the temperature is increased to 35 and $50{ }^{\circ} \mathrm{C}$, the critical stress for SIMT is increased. It is $404 \mathrm{MPa}$ at $20{ }^{\circ} \mathrm{C}, 495 \mathrm{MPa}$ at $35^{\circ} \mathrm{C}$ and $572 \mathrm{MPa}$ at $50{ }^{\circ} \mathrm{C}$ (see Fig. 1b). Such increase in the critical stress will retard the onset of plastic deformation and improve the wear resistance. For example, when tested at 35 and $50{ }^{\circ} \mathrm{C}$ under 50 $\mathrm{mN}$, no wear track was found, and the corresponding coefficients of friction were below 0.2. When under $100 \mathrm{mN}$, the stabilized coefficient of friction had kept around/below 0.25 , and the wear volume was at around $1.6 \times 10^{-4} \mathrm{~mm}^{3}$ 
$\left(35^{\circ} \mathrm{C}\right)$ and $0.69 \times 10^{-4} \mathrm{~mm}^{3}\left(50{ }^{\circ} \mathrm{C}\right)$, respectively. From 20 to $50{ }^{\circ} \mathrm{C}$, the wear volume decreased consistently with temperature rise, suggesting improved wear resistance due to increasing temperature.

However, when the average contact stress exceeds the yield stress of stress-induced martensite, plastic deformation of stress-induced martensite will dominate the wear process. Since the effective strain accommodation through reversible SIMT process can reduce the amount of plastic strain accumulation, the shape recovery ratio in the reversed transformation process will become an important factor in resisting wear. This is in consistency with the observations under $200 \mathrm{mN}$, in which an increased surface damage was observed at increased temperature accompanied with a decreased shape recovery ratio. When tested at 20,35 , and $50{ }^{\circ} \mathrm{C}$, the stabilized coefficient of friction was at $0.53,0.55$ and 0.65 , respectively (Fig. 3). Meanwhile the estimated wear volume was also increased with increasing temperature (Fig. 5b).

When the applied load is further increased hence the average contact stress is far exceeded the yield stress of stress-induced martensite, severe plastic deformation will occur which results in severe wear even in the early stage of the test. This explains the instability of the wear tests when the load was increased to $300 \mathrm{mN}$. An exception is the test at $20{ }^{\circ} \mathrm{C}$ under $300 \mathrm{mN}$ in which no instability had occurred throughout the test. This is likely due to the much better shape recovery property observed at this temperature (see Fig. $1 \mathrm{~b}$ ). At $20^{\circ} \mathrm{C}$, the shape recovery ratio was 0.95 which is better than those at $35^{\circ} \mathrm{C}(0.86)$ and $50^{\circ} \mathrm{C}(0.44)$. Hence, in addition to the applied load and the test temperature (this determines the critical stress for SIMT), shape recovery property also plays an important role in the wear resistance of SMAs. With other factors the same, better shape recovery property will lead to improved wear resistance. Hence, in order to improve the wear resistance of NiTi SMA, one can either increase the critical stress through metallurgical means (precipitation, grain size, alloying, manipulation of the transformation temperatures, etc.) or increase the superelastic shape recovery through microstructural alterations (for example textures), or both.

\section{Wear Behavior When $T>M_{\mathrm{d}}$}

When tested at 90 and $120{ }^{\circ} \mathrm{C}$, the SIMT has been prohibited and the deformation of austenite proceeds from elastic to plastic directly as shown in Fig. 1b. Under 50 $\mathrm{mN}$, the average contact stress was below the yield stress and elastic deformation dominated the wear process. In this case, the coefficient of friction was remained at a value below 0.3 , while the wear volume was at $1.3 \times 10^{-4} \mathrm{~mm}^{3}$ $\left(90{ }^{\circ} \mathrm{C}\right)$ and $2.3 \times 10^{-4} \mathrm{~mm}^{3}\left(120^{\circ} \mathrm{C}\right)$.
Under $100 \mathrm{mN}$, the average contact stress was still below the yield stress of $646 \mathrm{MPa}$ at $90{ }^{\circ} \mathrm{C}$ and $668 \mathrm{MPa}$ at $120{ }^{\circ} \mathrm{C}$, and elastic deformation dominated the wear process. Nevertheless, the actual contact stress within the small area immediately beneath the contact tip can exceed the yield stress of austenite hence introduce small amount of plastic deformation and cause observable wear damage. In this case, since the shape recovery associated with SIMT is not involved; the wear mechanism thus is similar to that of conventional materials.

With further increasing the load beyond the yield stress, more plastic deformation and wear will occur, and this explains results shown in Figs. 2d, e and 4d, e. For example, under $200 \mathrm{mN}$, the coefficient of friction had reached to around 0.72 and 0.65 for tests at 90 and $120{ }^{\circ} \mathrm{C}$, and the corresponding wear volume had reached to around $7.2 \times 10^{-4} \mathrm{~mm}^{3}$ and $7.8 \times 10^{-4} \mathrm{~mm}^{3}$, respectively. When the load was further increased to $300 \mathrm{mN}$, the surface was severely damaged in the very beginning of test due to severe plastic deformation.

\section{Summary of the Wear Behavior}

Comparing the values of the stabilized coefficient of friction and the wear volume as a function of load and temperature (Figs. 3, 5b), clear trends were seen. Two wear modes which are dominated by different deformation mechanisms were identified in different temperature regimes.

Mode I occurs when $A_{\mathrm{f}}<T<M_{\mathrm{d}}$. In this mode, the wear behavior of austenitic NiTi is highly temperaturesensitive. When the elastic deformation of austenite and stress-induced martensitic transformation dominate the wear process, the plastic deformation can be further retarded at increased temperature due to increased critical stress for SIMT. Meanwhile, better shape recovery property will also improve the wear resistance due to higher recoverable strain accommodation. Deformation strain accommodation through the reversible SIMT process has effectively reduced plastic strain accumulation in the wear process therefore caused less surface damage. However, if the contact stress exceeds the yield stress of stress-induced martensite when tested under extremely high load, wear resistance is deteriorated due to plastic deformation of stress-induced martensite.

Mode II occurs when $T>M_{\mathrm{d}}$. In this mode, the austenitic NiTi SMA lost its superelastic property and its deformation sequence is similar to that of conventional structural materials. Elastic-to-plastic deformation of austenite phase is the predominant mechanism for strain accommodation and wear resistance depends on the magnitude of contact stress/applied load. When the contact stress exceeds the yield stress of austenite, plastic 
deformation results in poor wear resistance and significant surface damage.

\section{Conclusions}

The wear behavior of austenitic NiTi SMA has been systematically investigated through wear tests at different loads and temperatures. Deformation mechanisms involved in the wear process were examined based on the observations on the coefficient of friction and surface wear features, estimated contact stresses, and the temperaturedependent deformation mechanisms of NiTi SMA. The results have shown that the wear behavior of austenitic NiTi SMA can be classified into two modes, Mode I and Mode II. Mode I occurs in the temperature range $A_{\mathrm{f}}<$ $T<M_{\mathrm{d}}$, while Mode II occurs when $T>M_{\mathrm{d}}$.

In Mode I, the wear behavior is determined by the interplay among contact stress, critical stress for SIMT, and the shape recovery ratio. A trend of increased wear resistance with increasing temperature was observed. This can be understood with the fact that the critical stress for SIMT increases with increasing temperature thus retards the plastic deformation. The good wear resistance observed in this mode is originated from the reversible stress-induced martensitic transformation that can effectively accommodate the deformation strain during wear test. Nevertheless, the shape recovery ratio also plays an important role in this process. However, when the contact stress exceeds the yield stress of stress-induced martensite, plastic deformation caused significant surface damage.

In Mode II, SMA lost its superelasticity and the deformation sequence is similar to other structural materials namely, elastic-to-plastic deformation. In this case, the wear resistance is predominantly determined by the contact stress and the yield stress of austenite. Poor wear resistance has been observed in this mode due to increased plastic deformation.

Acknowledgments L. Yan is grateful for the $\mathrm{PhD}$ research scholarship provided by the Nanyang Technological University.

\section{References}

1. Miyazaki S, Fukutsuji S, Taira M (1993) Application of Ti-Ni shape memory alloys to partial dentures. In: Proceedings of the international conference on martensitic transformations (Icomat92) (1993), pp 1235-1240

2. Qian L, Sun Q, Zhou Z (2008) The role of martensite reorientation in the fretting behaviour of nickel titanium shape memory alloy. Proc Inst Mech Eng Part J J Eng Tribol 222:887-897

3. El Feninat F, Laroche G, Fiset M, Mantovani D (2002) Shape memory materials for biomedical applications. Adv Eng Mater 4:91-104
4. Geetha M, Singh AK, Asokamani R, Gogia AK (2009) Ti based biomaterials, the ultimate choice for orthopaedic implants-a review. Prog Mater Sci 54:397-425

5. Liang YN, Li SZ, Jin YB, Jin W, Li S (1996) Wear behavior of a TiNi alloy. Wear 198:236-241

6. Michiardi A, Aparicio C, Planell JA, Gil FJ (2005) New oxidation treatment of NiTi shape memory alloys to obtain $\mathrm{Ni}$-free surfaces and to improve biocompatibility. J Biomed Mater Res B 77:43

7. Michiardi A, Aparicio C, Ratner BD, Planell JA, Gil J (2007) The influence of surface energy on competitive protein adsorption on oxidized NiTi surfaces. Biomaterials 28:586-594

8. Miyazaki S (1998) Medical and dental applications of shape memory alloys. Cambridge University Press, Cambridge

9. Pandit H, Glyn-Jones S, McLardy-Smith P, Gundle R, Whitwell D, Gibbons CLM, Ostlere S, Athanasou N, Gill HS, Murray DW (2008) Pseudotumours associated with metal-onmetal hip resurfacings. J Bone Joint Surg Brit 90B:847-851

10. Gandhi MV, Thompson BS (1992) Smart materials and structures. Chapman \& Hall, New York

11. Pan Q, Cho C (2007) The investigation of a shape memory alloy micro-damper for MEMS applications. Sensors 7:1887-1900

12. Abedini M, Ghasemi HM, Ahmadabadi MN (2009) Tribological behavior of NiTi alloy in martensitic and austenitic states. Mater Des 30:4493-4497

13. Clayton $P$ (1993) Tribological behavior of a titanium nickel-alloy. Wear 162:202-210

14. Gialanella S, Ischia G, Straffelini G (2008) Phase composition and wear behavior of NiTi alloys. J Mater Sci 43:1701-1710

15. Li DY (1996) Wear behaviour of TiNi shape memory alloys. Scripta Mater 34:195-200

16. Li DY (2000) Exploration of TiNi shape memory alloy for potential application in a new area: tribological engineering. Smart Mater Struct 9:717-726

17. Liu R, Li DY, Xie YS, Llewellyn R, Hawthorne HM (1999) Indentation behavior of pseudoelastic TiNi alloy. Scripta Mater 41:691-696

18. Ortin J, Planes A (1989) Thermodynamics of thermoelastic martensitic transformations. Acta Metall 37:1433-1441

19. Otsuka K, Shimizu K (1986) Pseudoelasticity and shape memory effects in alloys. Int Mater Rev 31:21

20. Otsuka K, Wayman CM (1998) Shape memory materials. Cambridge University Press, Cambridge

21. Qian LM, Zhou ZR, Sun QP (2005) The role of phase transition in the fretting behavior of NiTi shape memory alloy. Wear 259:309-318

22. Yan L, Liu Y, Liu E (2013) Wear behaviour of martensitic NiTi shape memory alloy under ball-on-disk sliding tests. Tribol Int 66:219-224

23. Yan L, Liu Y (2015) Effect of temperature on the wear behavior of NiTi shape memory alloy. J Mater Res 30:186-196

24. Firstov GS, Vitchev RG, Kumar H, Blanpain B, Van Humbeeck J (2002) Surface oxidation of NiTi shape memory alloy. Biomaterials 23:4863-4871

25. Liu Y, Li YL, Ramesh KT (2002) Rate dependence of deformation mechanisms in a shape memory alloy. Philos Mag A 82:2461-2473

26. Plietsch R, Ehrlich K (1997) Strength differential effect in pseudoelastic NiTi shape memory alloys. Acta Mater 45:2417-2424

27. McKelvey AL, Ritchie RO (2000) On the temperature dependence of the superelastic strength and the prediction of the theoretical uniaxial transformation strain in Nitinol. Philos Mag A 80:1759-1768

28. Liu YN, Yang H (2007) Strain dependence of the ClausiusClapeyron relation for thermoelastic martensitic transformations in NiTi. Smart Mater Struct 16:S22-S27 
29. Bhushan B (2010) Introduction to tribology. Wiley, New York

30. Gall K, Sehitoglu H, Chumlyakov YI, Kireeva IV (1999) Tension-compression asymmetry of the stress-strain response in aged single crystal and polycrystalline NiTi. Acta Mater 47:1203-1217

31. Orgeas L, Favier D (1998) Stress-induced martensitic transformation of a NiTi alloy in isothermal shear, tension and compression. Acta Mater 46:5579-5591

32. Rebelo N, Gong XY, Connally M (2003) Finite element analysis of nitinol's plastic behaviour. In: Proceedings of the international conference on shape memory and superelastic technologies SPIE (2003), p 6

33. Yan WY, Sun QP, Feng XQ, Qian LM (2007) Analysis of spherical indentation of superelastic shape memory alloys. Int $\mathbf{J}$ Solids Struct 44:1-17

34. Wood AJM, Clyne TW (2006) Measurement and modelling of the nanoindentation response of shape memory alloys. Acta Mater 54:5607-5615

35. Johnson KL (1985) Contact mechanics. Cambridge University Press, Cambridge 